\title{
THYROID HORMONE LEVELS IN NEONATAL HYPERBILIRUBINEMIA
}

\author{
Vithpala Praveena1, Mettu Pradeep Reddy², Jyotsna Bhagirath Jaju³, Rishabyadati, N. Sudheer ${ }^{5}$ \\ ${ }^{1}$ Assistant Professor, Department of Biochemistry, ESIC Medical College, Sanathnagar, Hyderabad, Telangana, India. \\ ${ }^{2}$ Associate Professor, Department of Paediatrics, ESIC Medical College, Sanathnagar, Hyderabad, Telangana, India. \\ 3Tutor, Department of Biochemistry, ESIC Medical College, Sanathnagar, Hyderabad, Telangana, India. \\ ${ }_{41}^{\text {st }}$ Year MBBS Student, ESIC Medical College, Sanathnagar, Hyderabad, Telangana, India. \\ ${ }_{5}^{5}$ Assistant Professor, Department of Dermatology, Osmania Medical College, Hyderabad, Telangana, India.
}

ABSTRACT
BACKGROUND
Neonatal jaundice affects $60 \%$ of full-term infants and $80 \%$ of preterm infants in the first three days of life. Congenital
Hypothyroidism (CH) is one of the most common preventable causes of mental retardation in children. Early diagnosis and
treatment prevent the devastating outcome of mental retardation. Studies have stated that hypothyroidism is one of the aetiologies
in severe hyperbilirubinemia. Prolonged jaundice is sometimes associated with congenital hypothyroidism, which appears to be
associated due to delayed maturation of hepatic uridine diphosphate glucuronyl transferase enzyme activity. The purpose of this
study was to investigate a relationship if any between neonatal thyroid-stimulating hormone (TSH), thyroxin (T4) and increased
levels of total bilirubin levels in the blood.

The aim of this study is to measure association between bilirubin levels and thyroid abnormality in new-borns.

\section{MATERIALS AND METHODS}

This is a case control study. The study group included 70 neonates admitted in neonatal ward at ESIC Medical College, Sanathnagar, who are full-term, normal birth weight, with no malformations and no history of hypothyroidism in mothers. Out of these, the neonates having serum total bilirubin $<15 \mathrm{mg} / \mathrm{dL}$ were considered as controls and neonates with serum total bilirubin $>15 \mathrm{mg} / \mathrm{dL}$ were considered as cases (i.e. neonates with severe hyperbilirubinemia are considered as cases). We have selected 35 cases and 35 controls. The sample size was taken for convenience during the study. We have performed thyroid profile in these neonates to see any association between hyperbilirubinemia and thyroid dysfunction, as thyroid dysfunction is one of the causes of pathological jaundice. We have taken cut-off of $15 \mathrm{mg} / \mathrm{dL}$ as less than $15 \mathrm{mg} / \mathrm{dL}$ of bilirubin is considered as physiological jaundice. The thyroid hormone levels in the present study were evaluated after 72 hours of postnatal age to avoid physiological changes in the hormonal levels during first 3 days of life. Bilirubin estimation was done by diazo method in fully automated analyser. Thyroid profile, i.e. T3, T4 and TSH were estimated in fully automated immunoassay analyser method by ECLIA (Electrochemiluminescence Immunoassay).

\section{RESULTS}

The mean concentration of total bilirubin is $11.0 \mathrm{mg} / \mathrm{dL} \pm 2.92$ in Controls and $15.99 \mathrm{mg} / \mathrm{dL} \pm 0.68$ in Subjects. Total TSH level is $2.81 \mu \mathrm{IU} / \mathrm{mL} \pm 2.05$ in Controls and $4.53 \mu \mathrm{IU} / \mathrm{mL} \pm 2.39$ in Subjects. Total T3 level is $1.56 \mathrm{ng} / \mathrm{mL} \pm 2.24$ depicted in Controls and 1.31 $\mathrm{ng} / \mathrm{mL} \pm 0.36$ in Subjects. Total T4 level is $12.40 \mu \mathrm{g} / \mathrm{dL} \pm 2.79$ in Controls and $10.77 \mu \mathrm{g} / \mathrm{dL} \pm 1.77$ in Subjects.

\section{CONCLUSION}

In this study, thyroid profile of both the cases and the controls were taken and were compared to find an association between the thyroid and the bilirubin levels. It was observed that there was a fall in thyroid levels (T3, T4), while an elevation in the TSH levels in the cases indicating alteration of thyroid hormone levels in hyperbilirubinemia.

\section{KEY WORDS}

Hyperbilirubinemia, Thyroid Hormone, Neonates, TSH, Bilirubin, Congenital Hypothyroidism, NBS.

HOW TO CITE THIS ARTICLE: Praveena V, Reddy MP, Jaju JB, et al. Thyroid hormone levels in neonatal hyperbilirubinemia. J. Evolution Med. Dent. Sci. 2018;7(28):3224-3228, DOI: 10.14260/jemds/2018/725

\section{BACKGROUND}

One of the common causes of mental retardation in children is congenital hypothyroidism, if detected early intellectual disability can be prevented.

'Financial or Other Competing Interest': None.

Submission 22-02-2018, Peer Review 23-06-2018,

Acceptance 29-06-2018, Published 09-07-2018.

Corresponding Author:

Dr. Mettu Pradeep Reddy,

Associate Professor,

Department of Paediatrics,

ESIC Medical College, Sanathnagar,

Hyderabad, Telangana, India.

E-mail: mettupradeepreddy@yahoo.com

DOI: $10.14260 /$ jemds $/ 2018 / 725$
Prevalence of Congenital Hypothyroidism worldwide is 1:3000 - 4000 live births and in India it is 1:2500 - 1:2800.1 But it could be the tip of iceberg, as there are no proper screening protocols in India. Clinical features of congenital hypothyroidism are often subtle after birth due to ameliorating effect of passage of maternal thyroid hormones transplacentally to foetus. ${ }^{2}$ Clinical features include poor feeding, increased sleeping time, hoarse cry, constipation and cold or mottled skin. Early diagnosis by screening for congenital hypothyroidism and treatment result in normal development. Thyroid hormones are essential for normal organ growth, development and function. The major secretory product of the thyroid is a prohormone (T4), which is activated in peripheral tissues by outer ring deiodination to T3. Diagnosis of hypothyroidism can be done by measuring 
T3, T4 and TSH measurement. If untreated, congenital hypothyroidism can lead to intellectual disability.

Neonatal hyperbilirubinemia, which is defined as a serum total bilirubin level exceeding $5 \mathrm{mg} / \mathrm{dL}$ is a frequent problem affecting new-borns. Jaundice in new-borns affects $60 \%$ of full-term infants and $80 \%$ of preterm infants in the first three days of life. ${ }^{3}$ Neonatal jaundice is yellowish discolouration of skin and sclera in a new-born by bilirubin. Hyperbilirubinemia is caused both by increased production of bilirubin, as the heme in red blood cells is broken down and by decreased bilirubin excretion due to inadequate hepatic conjugation and increased enterohepatic reabsorption. ${ }^{4}$ Prolonged jaundice can be associated with congenital hypothyroidism, which appears to be associated with the delayed maturation of hepatic uridine diphosphate glucuronyl transferase enzyme activity.5,6,7 Prolonged jaundice is seen in approximately $10 \%$ of new-borns with hypothyroidism. ${ }^{8}$ Hypothyroidism has been reported in studies, as the aetiology of jaundice that develops within the first week of life.6,9 The causes of pathological jaundice include haemolysis, breast milk jaundice, hypothyroidism, infections and extrahepatic biliary atresia.

The purpose of this study was designed to investigate a relationship if any between neonatal thyroid-stimulating hormone (TSH), thyroxin (T4) and total bilirubin levels in the blood, so that samples with any abnormal increase in bilirubin in first postnatal week of new-born can be screened for thyroid hormones which will help in detecting hypothyroidism in new-borns early.

New-born screening has been in practice for over 50 years since the development of screening procedure for metabolic disorder, phenylketonuria in 1960. Although, since 1972 the problem of congenital hypothyroidism has been resolved in developed countries by the implementation of new-born screening. The same cannot be said for developing countries that still have no new-born screening programs for congenital hypothyroidism. ${ }^{10,11}$ Neonatal Thyroid Screening Conference held in Tokyo in 1982 recommended new-born screening programs oriented to detect infants with elevated serum concentrations of TSH. Population based new-born screening (NBS) has been carried out in developed nations for the past 40 years. ${ }^{12}$ Many factors have limited the screening in India viz. high birth rate, low number of institutional births and poor awareness about preventive health. Most published studies on NBS in India have been carried out in a single-hospital setting. ${ }^{1,13}$

Congenital hypothyroidism is the result of an inability to produce adequate amounts of thyroid hormone. If left untreated, this congenital deficiency of thyroid hormone can result in mental retardation and stunted growth. New-borns may appear normal up to three months of age. If detected early (before three weeks) and maintained on appropriate levels of thyroid hormone medication, infants diagnosed with congenital hypothyroidism should have normal growth and development.

New-Born Screening (NBS) for congenital hypothyroidism is one of the major achievements of preventive medicine. Since diagnosis based on clinical findings is delayed in most instances because of few symptoms and signs, hypothyroidism in the new-born period is almost always overlooked and delayed diagnosis leads to the most severe outcome of congenital hypothyroidism, namely mental retardation.

As neonatal screening program is not implemented in several resource-poor settings, babies with congenital hypothyroidism present with a spectrum of clinical manifestations of varying severity. Pathological neonatal jaundice is one such non-specific manifestation of congenital hypothyroidism. The hyperbilirubinemia associated with congenital hypothyroidism can be unconjugated and conjugated, but few cases of conjugated hyperbilirubinemia with raised levels of transaminases have been described in literature. The American Academy of Pediatrics (AAP) guideline on management of hyperbilirubinemia recommends that every new-born be assessed for the risk of developing severe hyperbilirubinemia by using pre-discharge Total Serum Bilirubin (TSB) or Transcutaneous Bilirubin (TcB) measurements and/ or assessment of clinical risk factors before discharge.

Virtanen et al ${ }^{14}$ studied the clinical manifestations of congenital hypothyroidism in the first week of life and found that $57.3 \%$ of babies developed visible jaundice as compared to $27.8 \%$ in Euthyroid infants. Since diagnosis based on clinical findings is delayed in most instances because of few symptoms and signs, hypothyroidism in the new-born period is almost always overlooked and delayed diagnosis leads to the most severe outcome of congenital hypothyroidism (i.e.) mental retardation.

\section{Objective}

The objective is to measure association between bilirubin levels and thyroid abnormality in new-borns.

\section{MATERIALS AND METHODS}

This is a case control study. The study group included 70 neonates admitted in neonatal ward at ESIC Medical College, Sanathnagar from July to August 2017. Study was approved by Institutional Ethical Committee. Samples were collected from new-born babies after obtaining consent from parents. The study group included 70 neonates who are full-term, we have selected 35 cases and 35 controls. Normal birth weight, no malformation and no history of hypothyroidism in mothers. Out of these, those neonates having serum total bilirubin $<15 \mathrm{mg} / \mathrm{dL}$ were considered as controls and neonates with serum total bilirubin $>15 \mathrm{mg} / \mathrm{dL}$ are considered as cases (i.e. neonates with severe hyperbilirubinemia are grouped under cases). The sample size was taken for convenience during the study. We have performed thyroid profile in all the neonates to see the pattern of thyroid profile in severe hyperbilirubinemia. We have taken cut-off of $15 \mathrm{mg} / \mathrm{dL}$, because less than $15 \mathrm{mg} / \mathrm{dL}$ of bilirubin is considered as physiological jaundice. The thyroid hormone levels in the present study were evaluated after 72 hours of postnatal age to avoid physiological changes in the hormonal levels during first 3 days of life. ${ }^{15}$ Under all aseptic precautions, blood samples were collected in red topped vacutainers (plain tube). After transferring to laboratory, samples are centrifuged at $3000 \mathrm{rpm}$ for $5 \mathrm{mins}$, serum was separated. Serum bilirubin was estimated the same day followed by estimation of thyroid profile. Bilirubin estimation was done by Diazo method in Cobas fully automated analyser. Thyroid profile, i.e. T3, T4 and TSH were 
estimated in Cobas fully automated immunoassay analyser by ECLIA (Electrochemiluminescence Immunoassay) method.

\section{Statistical Analysis}

Chi-square test, student t-test and thyroid hormone levels computed by the Pearson's correlation coefficient were used for statistical analysis. Data was evaluated with GraphPad Prism 7.

\section{RESULTS}

During the study period between July and August, a total of about 70 neonates were examined for bilirubin and thyroid profile. The mean concentration of total bilirubin is 11.0 $\mathrm{mg} / \mathrm{dL} \pm 2.92$ depicted in Controls and $15.99 \mathrm{mg} / \mathrm{dL} \pm 0.68$ depicted in Subjects, total TSH level is $2.81 \mu \mathrm{IU} / \mathrm{mL} \pm 2.05$ in Controls and $4.53 \mu \mathrm{IU} / \mathrm{mL} \pm 2.39$ in Subjects depicted in Figure (3). Total $\mathrm{T} 3$ level is $1.56 \mathrm{ng} / \mathrm{mL} \pm 2.24$ depicted in Controls and $1.31 \mathrm{ng} / \mathrm{mL} \pm 0.36$ depicted in Subjects, Figure (1). Total T4 level is $12.40 \mu \mathrm{g} / \mathrm{dL} \pm 2.79$ depicted in Controls and $10.77 \mu \mathrm{g} / \mathrm{dL} \pm 1.77$ depicted in Subjects Figure (2). As per laboratory protocol of reference interval, we found that comparatively average TSH results is more in subjects with respect to the control group and $\mathrm{T} 3$ and $\mathrm{T} 4$ average is less when compared with control's average of results. By Pearson's correlation, total bilirubin levels showed a positive correlation with $\mathrm{T} 3$ and negative correlation with $\mathrm{T} 4$ and TSH, but it is not statistically significant. One case with borderline high TSH noted. Table (1) shows mean and standard deviation of $\mathrm{TSH}, \mathrm{T}_{4}, \mathrm{~T}_{3}$ and bilirubin in subjects.

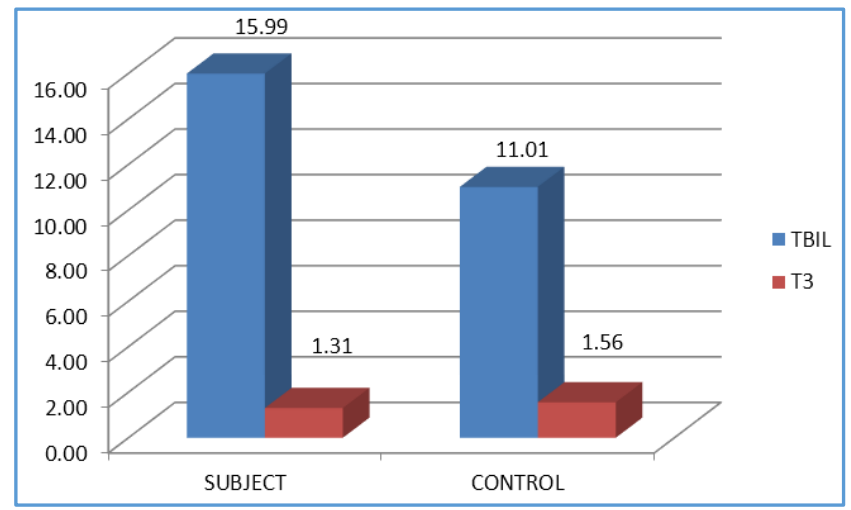

Figure 1. Diagrammatic representation of Mean Values of T3 Subject and Controls in Cases of TBI $>/<15 \mathrm{mg} / \mathrm{dL}$

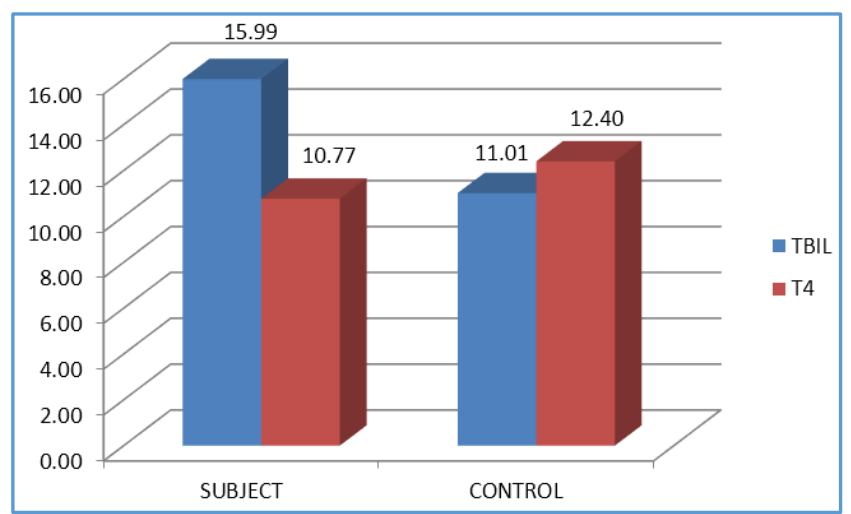

Figure 2. Diagrammatic representation of Mean Values of T4 Subject and Controls in cases of TBI $>/<15 \mathrm{mg} / \mathrm{dL}$

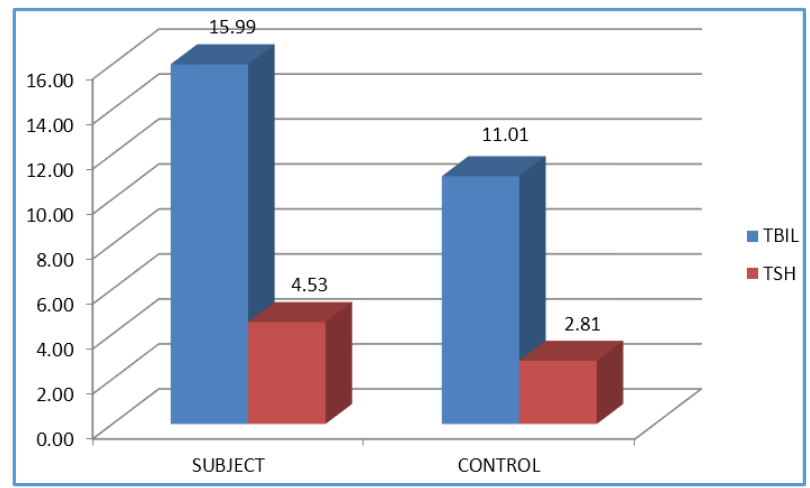

Figure 3. Diagrammatic representation of Mean Values of TSH and T. Bilirubin in Subjects and Controls

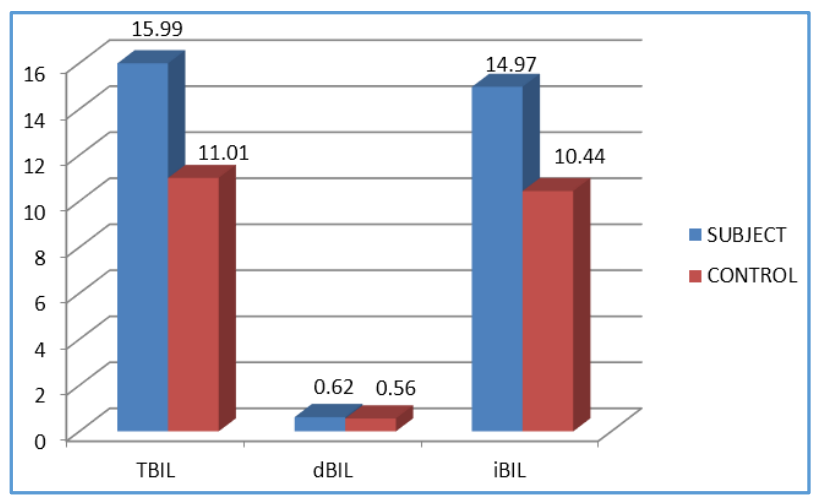

Figure 4. Diagrammatic representation of Mean Values of DBil, IBil Subject and Controls in cases of TBIL $>/<15$ $m g / d L$

\begin{tabular}{|c|c|c|c|}
\hline & $\begin{array}{c}\text { Cases } \\
\text { Mean } \pm \text { SD }\end{array}$ & $\begin{array}{c}\text { Controls } \\
\text { Mean } \pm \text { SD }\end{array}$ & P value \\
\hline Bilirubin & $15.99 \mathrm{mg} / \mathrm{dL} \pm 0.68$ & $11.0 \mathrm{mg} / \mathrm{dL} \pm 2.92$ & 0.36 \\
\hline $\mathrm{TSH}$ & $4.53 \mu \mathrm{IU} / \mathrm{mL} \pm 2.39$ & $2.81 \mu \mathrm{IU} / \mathrm{mL} \pm 2.05$ & 2.39 \\
\hline $\mathrm{T} 4$ & $10.77 \mu \mathrm{g} / \mathrm{dL} \pm 1.77$ & $12.40 \mu \mathrm{g} / \mathrm{dL} \pm 2.79$ & 1.77 \\
\hline $\mathrm{T} 3$ & $1.31 \mathrm{ng} / \mathrm{mL} \pm 0.36$ & $1.56 \mathrm{ng} / \mathrm{mL} \pm 2.24$ & 0.68 \\
\hline Table 1. Descriptive Statistics of TSH, Bilirubins, T4, T3- \\
Subjects and Controls \\
\hline
\end{tabular}

Table depicting Mean and Standard Deviation of TSH, T4, T3 and Bilirubin in Subject group.

\begin{tabular}{|c|c|c|c|c|}
\hline & T3 & T4 & TSH \\
\cline { 2 - 5 } & $\begin{array}{c}\text { Pearson } \\
\text { Correlation } \\
\text { (R value) }\end{array}$ & 0.026 & 0.239 & -0.069 \\
\hline $\begin{array}{c}\text { Total } \\
\text { Bilirubin } \\
\text { Levels }\end{array}$ & $\begin{array}{c}\text { Sig. } \\
\text { (2-tailed) } \\
\text { (P-value) }\end{array}$ & 0.882 & 0.167 & 0.694 \\
\cline { 2 - 5 } & $\mathrm{N}$ & 35 & 35 & 35 \\
\hline \multicolumn{2}{|c|}{ Table 2. Table depicting correlation between Total } \\
Bilirubin, T3, T4, TSH in Subjects \\
\hline
\end{tabular}

From the values it is found that there exists a negative correlation between the bilirubin levels and TSH levels, and between the bilirubin levels and T4 levels, but it is not statistically significant as shown in Table (2). There was a positive correlation observed between the bilirubin and T3 levels which is statistically significant as shown in Table (2). 


\section{DISCUSSION}

Congenital hypothyroidism is a preventable metabolic cause of mental retardation in children. Early diagnosis and treatment prevent the devastating outcome of mental retardation. Hypothyroidism can cause severe hyperbilirubinemia. Though studies have shown that the incidence of congenital hypothyroidism in India is 1:2500 to $1: 2800^{1}$, the incidence may be more than that stated in the study as new-born screening is not universal in India and is implemented only in few health systems. Neonatal hyperbilirubinemia is a common finding during the first postnatal week. Physiological jaundice occurs in first week of life in $60 \%$ of term and $80 \%$ of premature neonates. On the other hand, non-physiologic or pathologic jaundice occurs in $5-10 \%$ of new-borns, which require intervention. 16 Studies have stated that hypothyroidism as one of the aetiologies in severe hyperbilirubinemia and prolonged jaundice.5,6,7

In our study we have observed that thyroid hormone levels (T3, T4) are decreased in neonates having severe hyperbilirubinemia, but no significant correlation is noted. Results are similar to a study. ${ }^{17}$ Decreased hormone levels can cause prolonged unconjugated hyperbilirubinemia and appears to be associated with the delayed maturation of hepatic uridine diphosphate glucuronyl transferase (UDPG-T) enzyme activity.6,7 It is also observed that the decrease of thyroid hormones in case of hyperbilirubinemia is due to alterations of thyroid hormone metabolism in cases of unconjugated hyperbilirubinemia. These effects might involve inhibition of thyroid hormone uptake by their target cells. ${ }^{18}$ Though statistically significant correlation is not noted, but alteration in levels in thyroid hormones is seen in severe hyperbilirubinemia. Further study with large population is required to assess the relation between bilirubin and thyroid hormone obtained. Because of this association of thyroid hormones and severe hyperbilirubinemia, simultaneous measurement of T4, TSH and bilirubin levels can be a useful clinical tool for screening where universal screening for all neonates is not practical.

A prominent decrease in concentration of hepatic uridine diphosphate (UDP) glucuronic acid may be caused due to the absence of thyroid hormones, which is considerably low in infants as a result of the decrease in UDPG dehydrogenase activity. A delay in the bilirubin uptake may also be a response/ indication to the absence of thyroid hormones, which occurs due to the maturational changes in Ligandin. ${ }^{19}$

\section{CONCLUSION}

Congenital hypothyroidism is a preventable metabolic cause of mental retardation in children. Early diagnosis and treatment prevent the devastating outcome of mental retardation. Studies have stated that hypothyroidism as one of the aetiologies in severe hyperbilirubinemia and prolonged jaundice. In our study, we have observed that thyroid hormone levels (T3, T4) are decreased in neonates having severe hyperbilirubinemia, though statistically significant correlation is not noted, but alteration in levels in thyroid hormones is seen in severe hyperbilirubinemia. In view of this, simultaneous measurement of T4, TSH and bilirubin levels can be a useful clinical tool for screening where universal screening for all neonates is not practical.

\section{Limitations}

Since the calculated sample size was too high and thereby not feasible to include in this limited period of study, we had to limit the sample size for convenience.

\section{REFERENCES}

[1] Desai MP, Upadhye P, Colaco MP, et al. Neonatal screening for congenital hypothyroidism using the filter paper thyroxine technique. Indian J Med Res 1994;100:36-42.

[2] Rastogi MV, LaFranchi SH. Congenital hypothyroidism. Orphanet Journal of Rare Diseases 2010;5:17.

[3] Yadav A, Arora S, Saini V, et al. Influence of thyroid hormones on biochemical parameters of liver function: a case-control study in North Indian population. Internet Journal of Medical Update 2013;8(1):4-8.

[4] Burgos AE, Flaherman VJ, Newman TB. Screening and follow-up for neonatal hyperbilirubinemia: a review. Clinical Pediatrics (Phila) 2012;51(1):7-16.

[5] Singh B, Ezhilarasan R, Kumar P, et al. Neonatal hyperbilirubinemia and its association with thyroid hormone levels \& urinary iodine excretion. Indian Journal of Pediatrics 2003;70(4):311-5.

[6] Weldon AP, Danks DM. Congenital hypothyroidism and neonatal jaundice. Arch Dis Child 1972;47(253):469-71.

[7] MacGillivary MH, Crawford JD, Robey JS. Congenital hypothyroidism and prolonged neonatal hyperbilirubinemia. Pediatrics 1967;40(2):283-6.

[8] MacMahan JR, Stevenson DK, Oski FA. Physiologic jaundice. In: Taeush HW, Ballard RA, eds. Avery's Diseases of the newborn. $7^{\text {th }}$ edn. Philadelphia: Saunders 2000: p. 51-66.

[9] Tiker F, Gürakan B, Tarcan A, et al. Congenital hypothyroidism and early severe hyperbilirubinemia. Clinical Pediatrics (Phila) 2003;42(4):365-6.

[10] Buyukgebiz A. Congenital hypothyroidism clinical aspects and late consequences. Pediatr Endocrinol Rev 2003;1(Suppl 2):185-90.

[11] Yordam N, Ozon A. Neonatal thyroid screening: methods-efficiency-failures. Pediatr Endocrinol Rev 2003;1(Supp 2):177-84.

[12] Léger J, Olivieri A, Donaldson $M$, et al. European Society for Pediatric Endocrinology consensus guidelines on screening diagnosis and management of congenital hypothyroidism. J Clin Endocrinol Metab 2014;99(2):363-84.

[13] Sanghvi U, Diwakar KK. Universal newborn screening for congenital hypothyroidism. Indian Pediatrics 2008;45:331-2.

[14] Virtanen M. Manifestations of congenital hypothyroidism during the first week of life. Eur J Pediatr 1988;147(3):270-4.

[15] Fisher DA, Odell WD. Acute release of thyrotropin in the newborn. J Clin Invest 1969;48(9):1670-7.

[16] Afzal N, Qadir M, Qureshi S, et al. Urinary tract infection presenting as jaundice in neonates. J Pak Med Assoc 2012;62(7):735-7. 


\section{Jemds.com}

[17] Kayiran SM, Gurakan B. Correlation of third day TSH and thyroxine values with bilirubin levels detected by a neonatal screening system. Medical Journal of Bakirkoy 2010;6(3):117-20.

[18] Hablas WR, El-Nabarawy SK, Ibrahim NF, et al. Prevalence of Glucose-6-phosphate dehydrogenase and thyroid hormones deficiency in neonatal jaundice. The Egyptian Journal of Hospital Medicine 2014;55:165-74.

\section{Original Research Article}

[19] Chantoux F, Chuniaud L, Dessante M, et al. Competitive inhibition of thyroid hormone uptake into cultured rat brain astrocytes by bilirubin and bilirubin conjugates. Molecular and Cellular Endocrinology 1993;97(12):145-51. 